\title{
35 años de la PCR, la técnica que revolucionó la biología
}

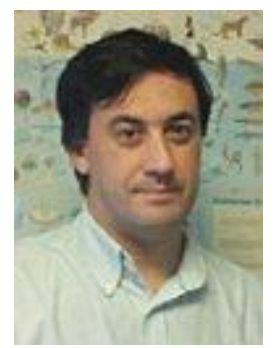

\section{molecular}

DOI: http://dx.doi.org/10.18567/sebbmdiv_RPC.2019.03.1

\section{Rafael Zardoya \\ Departamento de Biodiversidad y Biología Evolutiva, Museo Nacional de Ciencias Naturales (MNCN-CSIC)}

\section{Biografía Resumen}

Rafael Zardoya es licenciado en

Ciencias Biológicas (especialidad Bioquímica y Biología Molecular) por la Universidad Autónoma de Madrid (1989) y doctor en Ciencias

Biológicas por la Universidad Complutense de Madrid (1994).

Realizó su posdoctorado en la Universidad del Estado de Nueva York en Stony Brook(1997) y en el año 2000 entró en el Museo

Nacional de Ciencias Naturales donde es Profesor de Investigación CSIC desde el año 2008. Su carrera investigadora gira en torno al estudio de las bases genéticas de los procesos y mecanismos evolutivos

generadores de biodiversidad mediante la reconstrucción de filogenias moleculares utilizando métodos probabilísticos.

http://www.sebbm.es/

HEMEROTECA: http://www.sebbm.es/ES/divulgacionciencia-para-todos_10/la-ciencia-alalcance-de-la-mano-articulos-dedivulgacion_29
La reacción en cadena de la polimerasa o PCR permite amplificar de forma exponencial un fragmento de $A D N$ específico. Esta sencilla pero potente técnica aprovecha la capacidad natural de las ADN polimerasas de copiar las dos hebras de un ADN molde mediante la incorporación de nucleótidos a partir de un par de cebadores. Tiene numerosas aplicaciones en biología.

\section{Summary}

The polymerase chain reaction or PCR allows amplifying exponentially a specific DNA fragment. This simple but powerful technique is based on the natural capacity of DNA polymerases to copy the two strands of a template DNA through the incorporation of nucleotides starting from a pair of primers. It has numerous applications in biology.

El método científico trata de explicar los fenómenos naturales planteando hipótesis de trabajo y comprobando su certeza mediante la experimentación. Así, el avance científico está frecuentemente ligado a la aparición de novedades tecnológicas que expanden y refinan la capacidad de toma de los datos empíricos. En sus inicios, el estudio del ADN se realizaba de forma indirecta, por ejemplo mediante marcaje radioactivo. No fue posible manipular directamente el ADN hasta la década de 1970 cuando se descubrieron las enzimas de restricción y se construyeron los vectores de clonación plasmídicos y virales. Estas herramientas moleculares unidas al desarrollo en paralelo de los primeros métodos de secuenciación de ADN permitieron una expansión de la biología molecular y la primera caracterización del funcionamiento de numerosos genes. Sin embargo, no dejaban de ser técnicas tediosas que requerían de partida grandes cantidades de ADN, lo más puro e intacto posible y cuyo uso quedaba limitado a unas pocas especies modelo (ratones, moscas del vinagre, gusanos nematodos). Es en este contexto cuando el desarrollo de la reacción en cadena de la polimerasa, comúnmente conocida como PCR por sus siglas en inglés, revoluciona la biología molecular. El crédito de su invención lo tiene Kary B. Mullis, un químico que en 1983 trabajaba en la síntesis de oligonucleótidos en una compañía biotecnológica en California. Según su propio relato, la idea le vino durante un viaje nocturno en coche (1). Se le ocurrió que uniendo por complementariedad dos oligonucleótidos en las dos hebras opuestas del ADN a una distancia determinada, estos actuarían como cebadores de una DNA polimerasa que podría amplificar de forma exponencial el fragmento contenido entre ambos (2). Para poner en práctica su idea, Mullis concibió un ciclo en el que primero las dos hebras de ADN se desnaturalizaban en un baño a $95^{\circ} \mathrm{C}$, luego se les anillaban los cebadores en otro baño con una temperatura entre 45$55^{\circ} \mathrm{C}$ y finalmente se producía la elongación o replicación de las cadenas de ADN a la temperatura óptima de la DNA polimerasa en un baño a $72^{\circ} \mathrm{C}$. Este ciclo se debía repetir unas 30-35 veces hasta completar la PCR (Figura 1). La copia del ADN original a partir de los cebadores necesitaba como reactivos un tampón con el pH adecuado que además debía incluir magnesio (en forma de $\mathrm{MgCl}_{2}$ ) y los cuatro desoxinucleótidos (dNTPs) que se iban a incorporar a la cadena naciente, todo ello en un volumen final de unos $25 \mu \mathrm{l}$. Un primer problema al que Mullis se enfrentó fue que la DNA polimerasa de Escherichia coli se degradaba durante la etapa de desnaturalización por lo que había que añadir nuevo enzima en cada ciclo. Por suerte, algunos microorganismos viven de forma natural a altas temperaturas y sus

SE'BBM 
DNA polimerasas son termoestables (3). Es el caso de la denominada Taq polimerasa de Thermus aquaticus (una arquea encontrada en 1966 en los efluentes termales de Yellowstone) y que desde entonces se usa habitualmente en la PCR gracias a su gran capacidad de procesamiento. Otra DNA polimerasa interesante es la denominada Pfu de Pyrococcus furiosus que ofrece como ventaja la capacidad de corrección de errores.

En la actualidad, la PCR se realiza de forma automática en los denominados termocicladores, aparatos que realizan los ciclos completos usando el efecto Peltier que aumenta o disminuye la temperatura de un bloque simplemente invirtiendo la corriente eléctrica. Para mejorar la transmisión de la temperatura, los tubos de 0,2-0,5 ml tienen en la base cónica una pared muy fina y para evitar la condensación dentro del tubo, los termocicladores calientan la tapa del tubo durante el proceso. La PCR se suele terminar con un ciclo final de extensión a $72^{\circ} \mathrm{C}$ de unos 10 min para asegurar que cualquier ADN de cadena sencilla sea completado con la hebra complementaria. Terminada la reacción el bloque del termociclador queda a $4^{\circ} \mathrm{C}$ a la espera de recoger los tubos y correr un alícuota de su contenido en un gel de agarosa para comprobar si el fragmento de tamaño esperado ha sido amplificado correctamente (Figura 1). Dada la sensibilidad de la PCR es crucial asegurarse que durante el proceso de preparación de la reacción no haya contaminación con un ADN exógeno, extremando para ello la limpieza del laboratorio, así como de las micropipetas y los reactivos utilizados. La ausencia de contaminación se comprueba con un control negativo, un tubo en el que se incluyen los mismos reactivos usados en las muestras problema pero al que no se añade ADN molde. Los resultados de una PCR dependen en gran medida del grado de degradación del ADN original, de la posible existencia de inhibidores de la reacción y de la similitud de los cebadores a la secuencia del ADN molde. Los cebadores deben tener un tamaño de 20-30 nucleótidos, temperaturas de anillamiento similares y no ser complementarios entre sí ya que si no se podrían unir formando dímeros.

Con el tiempo se han desarrollado diferentes variantes de la PCR original para cubrir distintas necesidades. La PCR anidada consiste en amplificar un fragmento con unos cebadores y a continuación usar dicho fragmento como molde para una nueva PCR en la que se usan cebadores internos. Con ello se consigue aumentar la sensibilidad y la especificidad de la reacción. La PCR múltiple permite amplificar simultáneamente diversos fragmentos al utilizar varias combinaciones de pares de cebadores específicas de diferentes regiones del genoma. La PCR en tiempo real (Q-PCR) es quizás la variante más sofisticada que utiliza fluorescencia para monitorizar la amplificación del producto de PCR según se produce la reacción, lo que permite cuantificar la cantidad original de ADN molde.

La PCR es una técnica muy potente que se ha vuelto indispensable en cualquier laboratorio de biología molecular por sus numerosas aplicaciones. Por ejemplo, la amplificación y secuenciación por PCR de un fragmento del gen mitocondrial $\operatorname{cox} 1$ utilizando cebadores universales
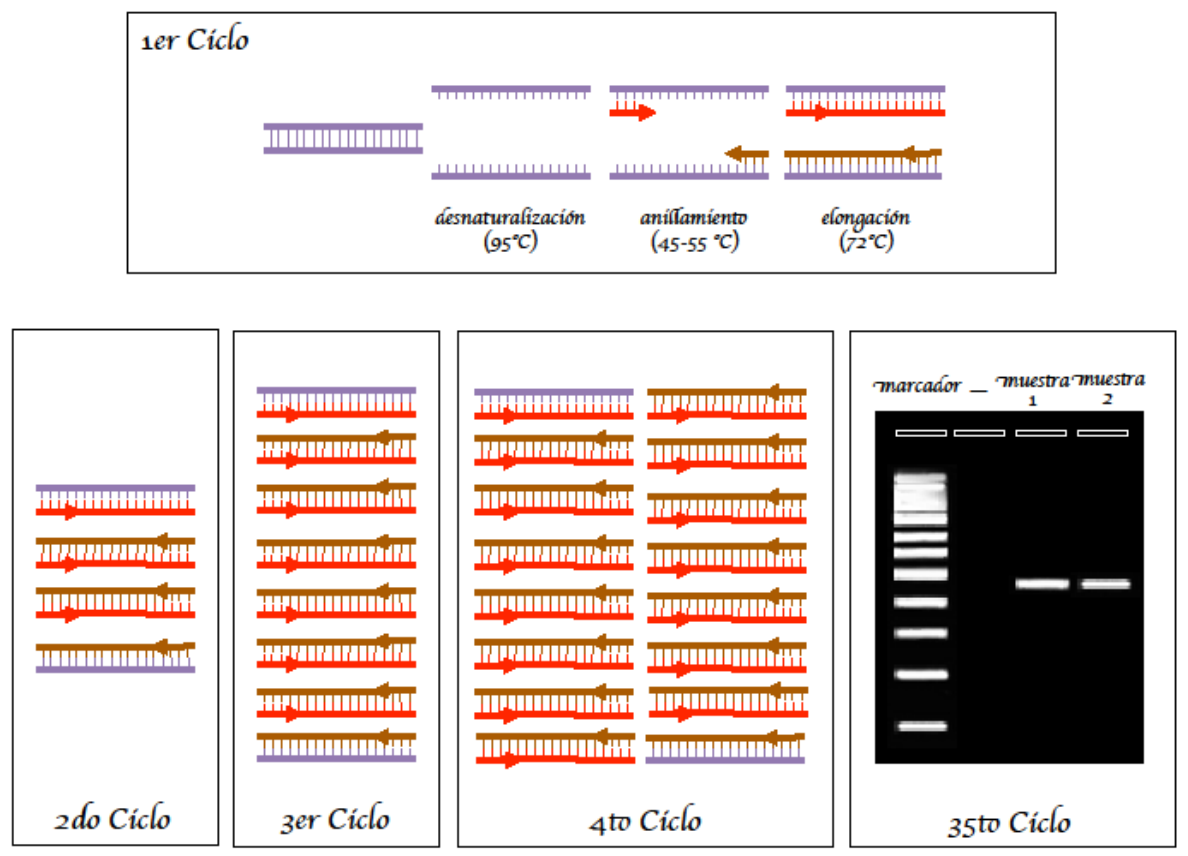

(diseñados en regiones conservadas evolutivamente) se utiliza como "código de barras" para identificar las diferentes especies de animales (4). La amplificación de unas secuencias repetitivas denominadas microsatélites se utiliza para determinar grados de parentesco e identificar individuos concretos. La PCR ha permitido amplificar genes de ADN de momias, de especímenes preservados en colecciones de museo o de muestras forenses (5). La PCR es una herramienta de diagnosis en epidemiología (bacterias, virus, parásitos) y medicina (cáncer, enfermedades hereditarias). En biología molecular, la PCR permite realizar mutagénesis dirigida mediante la introducción de cambios en los cebadores. La importancia y trascendencia de la PCR se puede medir por la rapidez en que Mullis obtuvo el premio Nobel, tan solo 10 años después de su invención (6). Pero, además, es una de esas pocas técnicas que han logrado salir del mundo restringido de los laboratorios y convertirse en conocida del gran público bien a través de series de televisión o a través de los diagnósticos rutinarios de hospitales. En la actualidad solo la secuenciación masiva y la técnica CRISPR-cas9 pueden competir con la PCR en llevarse el título de técnica más revolucionaria en biología molecular.

\section{Referencias}

1. K.B. Mullis. The unusual origin of the polymerase chain reaction. Sci. Am. 1990 Apr. 262(4):56-

65.https://pdfs. semanticscholar.org/14bf/9cc89 c9885d7ad46a384d0e5661ac07c752f.pdf

2. R.K. Saiki, D.H. Gelfand, S. Stoffel, S.J.

Scharf, R. Higuchi, G.T. Horn, K. B. Mullis and H.A. Erlich. Primer-directed enzymatic amplification of DNA with a thermostable DNA polymerase. Science 1988 Jan 29. 239(4839):487-

491.http://citeseerx.ist.psu.edu/viewdoc/downl oad?doi=10.1 1.466.4113\&rep=rep1\&type=pdf 3. S. Ishino and Y. Ishino. DNA polymerases as useful reagents for biotechnology - the history of developmental research in the field. Front Microbiol. 2014 5: 465. https://www.ncbi.nlm.nih.gov/pmc/articles/PM C4148896/pdf/fmicb-05-00465.pdf 4. P.D.N. Hebert, A. Cywinska, S.L. Balland J.R. de Waard. Biological identifications through DNA barcodes. Proc Biol Sci. 2003 270:313-321.

https://www.ncbi.nlm.nih.gov/pmc/articles/PM C1691236/pdf/12614582.pdf

5. M. Arenas, F. Pereira, M. Oliveira, N. Pinto et al. Forensic genetics and genomics: Much more than just a human affair. PLoS Genet 2017 Sep. 13(9): e1006960.

https://www.ncbi.nlm.nih.gov/pmc/articles/PM C5608170/pdf/pgen.1006960.pdf

6.K.B. Mullis. The polymerase chain reaction. Nobel Lecture Dec. 8, 1993.

https://www.nobelprize.org/prizes/chemistry/19 93/mullis/lecture/ 